\title{
Down-regulated donor-specific T-cell reactivity during successful tapering of immunosuppression after kidney transplantation
}

\author{
N. M. VAN BESOUW*, B. J. VAN DER MAST*, P. DE KUIPER*, P. J. H. SMAK GREGOOR*, LENARD M. B. \\ VAESSEN*, J. N. M. IJZERMANS $\dagger$, T. VAN GELDER* \& W. WEIMAR**Departments of Internal Medicine and \\ $\dagger$ General Surgery, University Hospital Rotterdam-Dijkzigt, Rotterdam, The Netherlands
}

(Accepted for publication 4 January 2002)

\begin{abstract}
SUMMARY
Stable cadaveric renal transplant patients were routinely converted from cyclosporin A (CsA) to either azathioprine (AZA) or mycophenolate mofetil (MMF) 1 year after transplantation to reduce the side effects of long-term immunosuppressive therapy. Thereafter, the AZA and MMF dose was gradually tapered to $50 \%$ at 2 years after transplantation. We questioned whether a reduction of immunosuppressive treatment results in a rise of donor-specific T-cell reactivity. Before transplantation (no immunosuppression), 1 year (high dose immunosuppression) and 2 years (low dose immunosuppression) after transplantation, the T-cell reactivity of peripheral blood mononuclear cells (PBMC) against donor and third-party spleen cells was tested in mixed lymphocyte cultures (MLC) and against tetanus toxoid (TET) to test the general immune response. We also measured the frequency of donor and thirdparty reactive helper (HTLpf) and cytotoxic (CTLpf) T-lymphocyte precursors in a limiting dilution assay. Donor-specific responses, calculated by relative responses $(\mathrm{RR}=$ donor/third-party reactivity), were determined. Comparing responses after transplantation during high dose immunosuppression with responses before transplantation (no immmunosuppression), the donor-specific MLC-RR $(P=$ 0.04), HTLp-RR $(P=0.04)$ and CTLp-RR $(P=0.09)$ decreased, while the TET-reactivity did not change. Comparing the responses during low dose with high dose immunosuppression, no donorspecific differences were found in the MLC-RR, HTLp-RR and CTLp-RR, although TET-reactivity increased considerably $(P=0 \cdot 0005)$. We observed a reduction in donor-specific T-cell reactivity in stable patients after renal transplantation during in vivo high dose immunosuppression. Tapering of the immunosuppressive load had no rebound effect on the donor-specific reactivity, while it allowed recovery of the response to nominal antigens.
\end{abstract}

Keywords MLC HTLpf CTLpf tapering immunosuppression

\section{INTRODUCTION}

In the early 1980s, it was proven that cyclosporin A (CsA) is more effective than azathioprine (AZA) in preventing acute rejection of renal allografts [1-3]. However, the chronic use of CsA is associated with multiple side effects, e.g. nephrotoxicity and hypertension $[2,4,5]$. To minimize these side effects, and in an attempt to preserve benefits on graft survival, administration of CsA for one year and thereafter, conversion to the less nephrotoxic drugs AZA [6-10] or mycophenolate mofetil (MMF) [10], would be an option. To reduce the long-term side effects (cancer) [11] of immunosuppressive agents, and to improve the quality of life after transplantation, the AZA, MMF or prednison (Pred) dose can be

Correspondence: Dr N. M. van Besouw, University Hospital Rotterdam-Dijkzigt, Department of Internal Medicine, Room Bd299, PO Box 2040, NL-3000 CA Rotterdam, The Netherlands.

E-mail: vanbesouw@inwl.azr.nl tapered $[10,12,13]$, provided this is not accompanied by rejection. In some patients, it is even possible to discontinue the immunosuppression completely [14,15], suggesting that donor-specific non-responsiveness can occur following transplantation.

In vitro studies have demonstrated that donor-specific hyporesponsiveness can be observed in mixed lymphocyte culture (MLC), cell-mediated lympholysis (CML), and cytotoxic (CTLpf) and helper (HTLpf) T-lymphocyte precursor frequencies [16-21]. Some studies have described T-cell reactivity before (no immunosuppression) and after transplantation (high dose immunosuppression) [16,21-24]. To date, only a few studies have measured T-cell reactivity before (high dose immunosuppression) and after tapering (low dose immunosuppression) immunosuppression, although in a small number of patients $[17,20,25,26]$. All these results suggested that transplant acceptance might be reflected by in vitro donor antigen-specific hyporeactivity.

To our knowledge, no controlled study has been performed in stable renal transplant patients to investigate T-cell reactivity 
before transplantation, during high dose immunosuppression and during tapered or low dose immunosuppression. We questioned what effect the reduction of immunosuppressive treatment could have on donor-specific responses. Therefore, we studied T-cell reactivity in 20 stable renal transplant recipients before transplantation (no immunosuppression), one year after transplantation and treatment with CsA and Pred (high dose immunosuppression), and two years after transplantation when the patients were successfully converted and successfully (without the occurrence of acute rejection) tapered in their treatment with AZA or MMF and Pred (low dose immunosuppression). Donorspecific reactivity was measured in MLC and in limiting dilution assays (LDA) to study HTLpf and CTLpf. The non-HLA-specific TET-reactivity was used to test the general immune response.

\section{MATERIALS AND METHODS}

\section{Patients}

Between September 1995 and January 1997, 80 cadaveric kidney transplantations were performed in Rotterdam. Forty-six patients with stable graft function 1 year after transplantation, without acute rejection in the last 6 months, were routinely converted from CsA (whole blood trough level: $\pm 150 \mathrm{ng} / \mathrm{ml}$ ) and Pred $(10 \mathrm{mg} / \mathrm{day})$, to either AZA $(2 \mathrm{mg} / \mathrm{kg} / \mathrm{day})(n=22)$ or $\mathrm{MMF}$ $(2 \mathrm{~g} /$ day $)(n=24)$ and Pred $(10 \mathrm{mg} /$ day $)$, in a prospective and randomised controlled study [10]. CsA was gradually discontinued within 1 month after the start of AZA or MMF medication. In stable patients, the AZA and MMF dose was reduced to $75 \%$ at 4 months and to $50 \%$ at 8 months after conversion, reaching maintenance treatment of $1 \mathrm{mg} / \mathrm{kg} /$ day AZA or $1 \mathrm{~g} /$ day MMF. Thirty stable patients were able to complete the whole study period of 2 years ( 4 months after the last dose reduction). From 20 patients, PBMC and donor spleen cells were available to study the T-cell reactivity before renal transplantation (no immunosuppression), 1 year after transplantation (CsA therapy; high dose immunosuppression) and 2 years after transplantation (tapered AZA ( $n$ $=10)$ or MMF $(n=10)$ treatment; low dose immunosuppression). The mean number of HLA-A, -B and -DR mismatches on broad antigens was $1.9 \pm 1.3$ (s.d.) (range: $0-4$ ) in the AZA group, and $1 \cdot 8 \pm 1 \cdot 6$ (range $0-4$ ) in the MMF group.

\section{Peripheral blood mononuclear cells (PBMC) and spleen cell sampling}

PBMC samples were isolated as described before [27] and stored at $-140^{\circ} \mathrm{C}$ until use.

Spleen cells were obtained by mechanical dissociation of small pieces of spleen derived from the organ donor [27]. Subsequently, the cell suspension was filtered through a $40 \mu \mathrm{m}$ cell strainer (Falcon, Franklin Lakes, NJ, USA) and washed. Thereafter, the cells were centrifuged over a Ficoll-Paque (Amersham Pharmacia Biotech, Uppsala, Sweden) density gradient, collected, washed and stored at $-140^{\circ} \mathrm{C}$.

\section{Mixed lymphocyte culture (MLC) and tetanus toxoid (TET) stimulation}

For MLC and TET stimulation, $100 \mu \mathrm{l}$ of a $5 \times 10^{4}$ PBMC suspension in culture medium (RPMI 1640-DM (GIBCO BRL, Paisley, UK) supplemented with $2 \mathrm{mM}$ L-glutamine (GIBCO), $100 \mathrm{IU} / \mathrm{ml}$ penicillin (BioWhittaker, Verviers, Belgium), $100 \mu \mathrm{g} / \mathrm{ml}$ streptomycin (BioWhittaker) and $10 \%$ pooled, heat-inactivated human serum that was tested for adequate cell-growth support in
MLC) were added in triplicate wells in a round-bottomed 96-well plate (Nunc, Roskilde, Denmark) to $100 \mu$ culture medium containing: (a) $5 \times 10^{4}$ irradiated (45 Gy) spleen cells derived from the donor; (b) $5 \times 10^{4}$ irradiated (45 Gy) spleen cells derived from a third-party which did not share HLA antigens with the donor and patient. For each patient the same third-party cells were used in all experiments; (c) TET (RIVM, Bilthoven, The Netherlands) at $7 \cdot 5 \mathrm{lf} / \mathrm{ml}$ final concentration as nominal antigen to test the general immune response; (d) phytohaemagglutinin M (PHA; 1:100 final dilution; Difco Laboratories, Detroit, MI, USA) to control the viability of the cells; and (e) culture medium. After 7 days ( 3 days in the case of the PHA control) of incubation at $37^{\circ} \mathrm{C}$ in a humidified atmosphere of $5 \% \mathrm{CO}_{2}$ in air, cell proliferation was measured by incorporation of ${ }^{3} \mathrm{H}$-thymidine $(0.5 \mu \mathrm{Ci} /$ well: Amersham Pharmacia Biotech) which was added during the last $8 \mathrm{~h}$ of culture. The cells were harvested as described before [27]. The mean counts per minute (cpm) were determined and the stimulation index (SI) was calculated by the ratio of the cpm obtained in the presence of antigen to the cpm in the absence of antigen.

\section{Limiting dilution assay ( $L D A)$}

Limiting dilution cultures were set up in 96-well U-bottomed tissue plates (Nunc). Twenty-four replicates of graded number PBMC responders were titrated in seven-step double dilutions, starting from $5 \times 10^{4}$ to $781 \mathrm{PBMC} /$ well, and stimulated with irradiated (45 Gy) donor or third-party spleen cells $\left(5 \times 10^{4}\right.$ cells/well) in $200 \mu \mathrm{l}$ culture medium. Additionally, 24 wells contained stimulator cells alone.

After 3 days of culture, $100 \mu$ l of the supernatant fluid were harvested and transferred to U-bottomed 96-well plates (Nunc). These plates were stored at $-20^{\circ} \mathrm{C}$ until use in a bio-assay to measure IL-2 production, using the IL-2-dependent CTLL-2 cell line, and to determine the HTLpf as described below.

The remaining cells were refreshed with $100 \mu$ l culture medium containing recombinant IL-2 (20 U/well, $12 \cdot 2 \mathrm{ng} / \mathrm{ml}$ IL-2; proleukin: Chiron BV, Amsterdam, The Netherlands). Each well was individually tested for cytolytic activity against $5 \times 10^{3}$ Europiumdiethylenetriaminepentaacetate-labelled target cells (Eu-DTPA: Fluka, Buchs, Switzerland and Sigma, St. Louis, MO, USA). In the case of donor stimulation, T-cell blasts of donor origin were used as targets and for third-party stimulation, T-cell blasts of the third-party spleen cells were used as targets [27]. After $4 \mathrm{~h}$ of incubation at $37^{\circ} \mathrm{C}$ in a humidified atmosphere of $5 \% \mathrm{CO}_{2}$, the plates were centrifuged for $5 \mathrm{~min}$ at $600 \mathrm{~g}$ and $20 \mu \mathrm{l}$ of the supernatant fluid were transferred to 96-well plates with a low background fluorescence (fluoroimmunoplate; Nunc). Additionally, $100 \mu$ l of enhancement solution (LKB-Wallac, Turku, Finland) were added to each well. Plates were stored in the dark at room temperature until the fluorescence of the released Europium was measured in a time-resolved fluorometer (Victor 1420 Multilabel Counter, LKB-Wallac, Turku, Finland). Fluorescence was expressed in counts per second (cps). As a control for every target cell, spontaneous lysis (target cells + culture medium) and maximum lysis (target cells $+1 \%$ Triton $\mathrm{X}-100$ ) was determined.

\section{Helper T-lymphocyte precursor frequency (HTLpf)}

To determine the HTLpf, the concentration of IL-2 was determined in the culture supernatant fluid using the IL-2-dependent murine CTLL-2 cell line, which is sensitive for human IL-2 and not for human IL-4 [28]. 
The HTLpf was determined as described before [27]. Briefly, the LDA-culture supernatant fluid was thawed, the CTLL-2 cells were extensively washed and resuspended at a concentration of $5 \times 10^{4}$ cells $/ \mathrm{ml}$. Subsequently, the CTLL- 2 cells were added to $100 \mu$ l serially-diluted recombinant IL-2 (Chiron; 100-0·05 U/ml) or sample supernatant fluid. After $24 \mathrm{~h}$ of incubation, with the final $4 \mathrm{~h}$ in the presence of $0.5 \mu \mathrm{Ci} /$ well ${ }^{3} \mathrm{H}$-thymidine, the cells were harvested and the counts per minute (cpm) were determined.

\section{Statistical analysis}

The mean cps (CTLpf) and cpm (HTLpf) with their standard deviation (s.d.) of the wells, in which only stimulator cells were present, were considered as background. Experimental wells were scored positive if the counts in that well exceeded the mean $+(3$ $\times$ s.d.) of the wells in which only stimulator cells were present. For each cell concentration, the number of negative wells was determined and used to calculate the frequency with a computer program designed by Strijbosch et al. [29].

The CTLpf and HTLpf (expressed as the number of CTLp or HTLp per $10^{6}$ cells) and the $95 \%$ confidence interval (CI) were calculated by the Jackknife procedure for maximal likelihood [29]. The calculated frequencies were accepted when the goodness-of-fit did not exceed 12 .

The donor-specific response was expressed as the relative response (RR), and calculated by the ratio of the donor reactivity to the third-party reactivity to correct for non-specific changes in T-cell reactivity.

The paired Wilcoxon signed rank test was used to test the difference between no, high and low dose immunosuppression. Two-sided $P$-values $\leq 0 \cdot 05$ were considered significant.

\section{RESULTS}

\section{Donor-specific $M L C$}

Neither the donor nor the third-party reactive MLC changed after transplantation when analysed in no versus high, or high versus low dose immunosuppression: median and range donor MLC (SI) 97 (1-327) versus 21 (1-852); $P=0 \cdot 87$, or 21 (1-852) versus $80 \cdot 5$ (1-964), $P=0 \cdot 87$, respectively; third-party MLC (SI) 176 (17-491) versus 146 (4-2187), $P=0 \cdot 89$, or 146 (4-2187) versus 288 (8-1031), $P=0 \cdot 13$, respectively.

The donor-specific MLC, calculated by the MLC-RR, had decreased significantly 1 year after transplantation compared with pre-transplantation (Fig. 1: no immunosuppression versus high dose immunosuppression: $P=0 \cdot 04)$. Two years after transplantation, when the immunosuppressive therapy was tapered, the
MLC-RR had not changed $(P=0 \cdot 92)$. No significant increase or decrease in MLC-RR compared with the reactivity under CsA treatment was found between patients who were treated with low dose AZA and those on low dose MMF $(P=0 \cdot 78$; Table 1$)$.

\section{Tetanus toxoid (TET) reactivity}

TET reactivity did not change after transplantation under high dose immunosuppression compared with pre-transplantation (no immunosuppression) $(P=0 \cdot 86)$ (Fig. 2). In contrast, when the immunosuppressive dose was tapered, TET reactivity increased significantly (Fig. 2: high versus low dose immunosuppression: $P=0 \cdot 0005)$. No difference was found between the patients converted to low dose AZA and low dose MMF $(P=0 \cdot 91$; Table 1$)$.

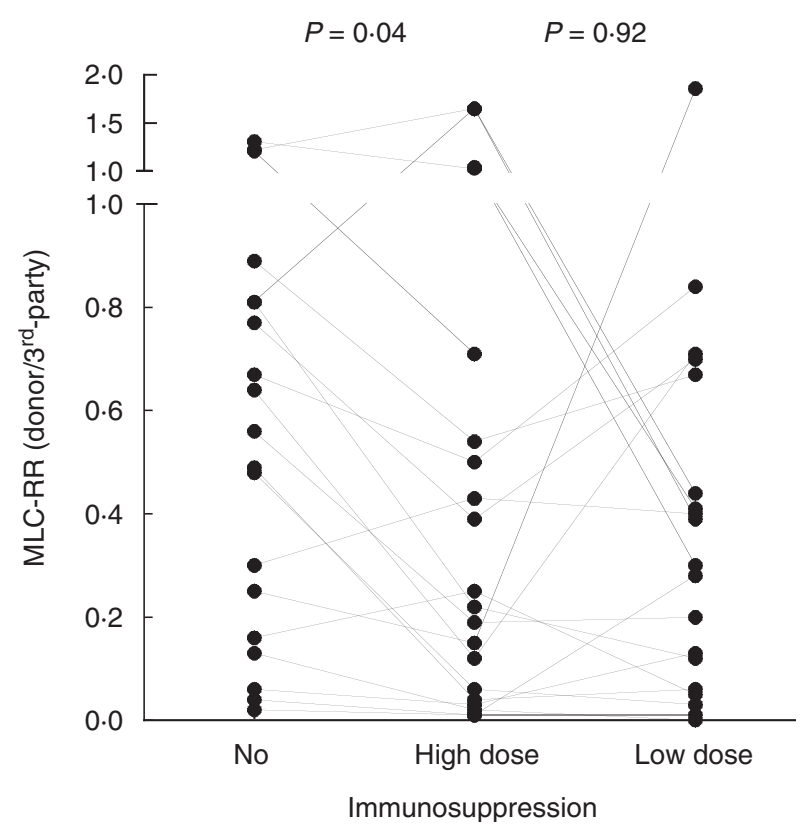

Fig. 1. Relative response (RR: donor/3rd-party reactivity) in MLC of 20 kidney transplant patients measured before transplantation (no immunosuppression), during treatment with high dose immunosuppression (1 year after transplantation: CsA treatment (trough level: $\pm 150 \mathrm{ng} / \mathrm{ml}$ ) and Pred $(10 \mathrm{mg} /$ day $))$, and during treatment with low dose immunosuppression (2 years after transplantation: $1 \mathrm{mg} / \mathrm{kg} /$ day AZA or $1 \mathrm{~g} /$ day MMF and Pred $(10 \mathrm{mg} / \mathrm{day}))$. No cells were available from one patient before transplantation and from one patient during treatment with low dose immunosuppression.

Table 1. Change in T-cell reactivity (MLC-RR, TET, HTLp-RR, and CTLp-RR) in PBMC after conversion from CsA to low dose azathioprine (AZA) or mycophenolate mofetil (MMF) compared with treatment with CsA

\begin{tabular}{|c|c|c|c|c|c|}
\hline & & MLC-RR & TET & HTLp-RR & CTLp-RR \\
\hline \multirow[t]{2}{*}{ AZA } & Median & $0 \cdot 005$ & 26 & $-0 \cdot 046$ & $-0 \cdot 007$ \\
\hline & Range & $-1 \cdot 209-0 \cdot 586$ & $0-430$ & $-0 \cdot 271-10 \cdot 000$ & $-0 \cdot 253-0 \cdot 094$ \\
\hline \multirow[t]{3}{*}{ MMF } & Median & $-0 \cdot 021$ & $45 \cdot 5$ & $0 \cdot 178$ & $0 \cdot 106$ \\
\hline & Range & $-1 \cdot 260-1 \cdot 705$ & $-25-580$ & $-2 \cdot 313-0 \cdot 231$ & $-0 \cdot 066-3 \cdot 105$ \\
\hline & $P$-value & 0.78 & 0.91 & $0 \cdot 16$ & $0 \cdot 19$ \\
\hline
\end{tabular}




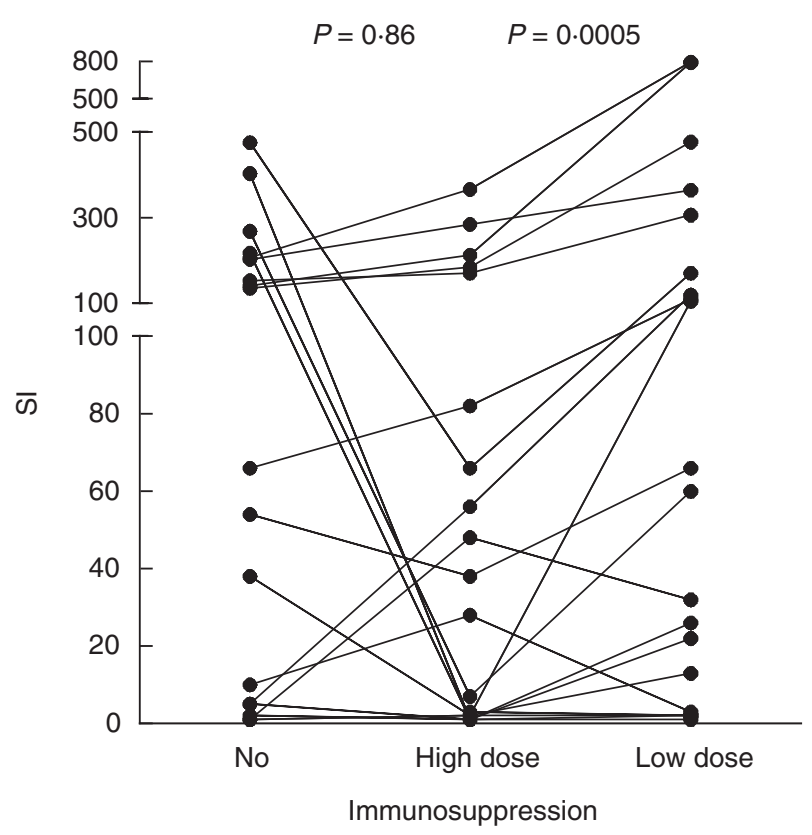

Fig. 2. Proliferative capacity (stimulation index $(\mathrm{SI})=$ ratio of counts per minute $(\mathrm{cpm})$ obtained in the presence of antigen, to the $\mathrm{cpm}$ in the absence of antigen) to tetanus toxoid (TET) of 20 kidney transplant patients measured before transplantation (no immunosuppression), during treatment with high dose immunosuppression (1 year after transplantation: CsA treatment (trough level: $\pm 150 \mathrm{ng} / \mathrm{ml}$ ) and Pred $(10 \mathrm{mg} /$ day $))$, and during treatment with low dose immunosuppression ( 2 years after transplantation: $1 \mathrm{mg} / \mathrm{kg} /$ day AZA or $1 \mathrm{~g} /$ day $\mathrm{MMF}$ and Pred $(10 \mathrm{mg} /$ day $))$. No cells were available from one patient before transplantation.

Helper T-lymphocyte precursor frequency (HTLpf)

The donor and third-party reactive HTLpf were comparable before and after transplantation, when analysed in no versus high, or high versus low dose immunosuppression: median and range donor HTLpf (\#/106 PBMC) $96 \cdot 5$ (0-548) versus $23 \cdot 5$ (0-528), $P$ $=0 \cdot 11$, or $23 \cdot 5(0-528)$ versus $29(0-481), P=0 \cdot 50$, respectively; median and range third-party HTLpf (\#/10 PBMC) 187.5 (9-804) versus 103 (2-476), $P=0 \cdot 47$, or 103 (2-476) versus 222 (2-806), $P=0 \cdot 04$, respectively.

The donor-specific HTLpf calculated by the HTLp-RR was lower after transplantation when high doses of immunosuppression were administered than before transplantation (no immunosuppression) (Fig. 3: $P=0 \cdot 04)$. However, the HTLp-RR remained unchanged when the immunosuppressive dose was tapered $(P=0 \cdot 13)$. Consequently, a significant difference was still found between no immunosuppression and low dose immunosuppression $(P=0 \cdot 02)$. We found no difference in HTLp-RR compared with the reactivity under CsA treatment between low AZA and low MMF treatment $(P=0 \cdot 16$; Table 1$)$.

\section{Cytotoxic T-lymphocyte precursor frequency (CTLpf)}

Neither donor nor third-party reactive CTLpf changed after transplantation, when analysed in no versus high, or high versus low dose immunosuppression: median and range donor CTLpf (\#/10 ${ }^{6}$ PBMC) 19 (0-131) versus $9(0-172), P=0 \cdot 33$, or $9(0-172)$ versus 13 (0-115), $P=0.93$, respectively; third-party CTLpf $\left(\# / 10^{6}\right.$ PBMC) 122 (4-294) versus 89 (19-221), $P=0 \cdot 39$, or 89 (19-221) versus 91 (3-520), $P=0 \cdot 21$, respectively.

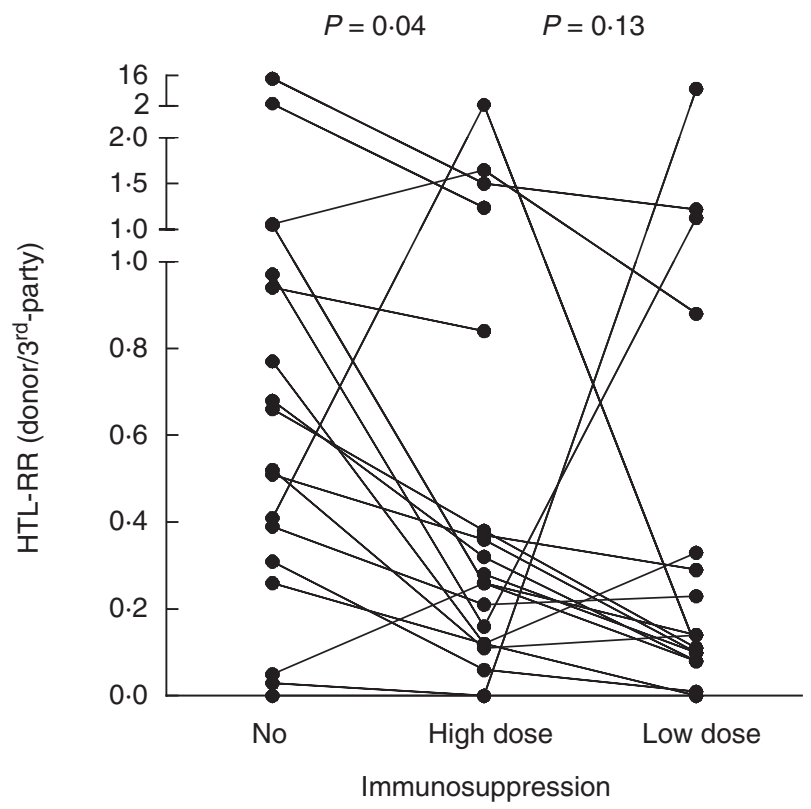

Fig. 3. Relative response (RR: donor/3rd-party reactivity) in HTLp of 20 kidney transplant measured before transplantation (no immunosuppression), during treatment with high dose immunosuppression (1 year after transplantation: CsA treatment (trough level: $\pm 150 \mathrm{ng} / \mathrm{ml}$ ) and Pred $(10 \mathrm{mg} /$ day $))$, and during treatment with low dose immunosuppression ( 2 years after transplantation: $1 \mathrm{mg} / \mathrm{kg} /$ day AZA or $1 \mathrm{~g} / \mathrm{day}$ MMF and Pred $(10 \mathrm{mg} /$ day $))$. No cells were available from two patients before transplantation and from two patients during treatment with low dose immunosuppression.

When patients were not treated with immunosuppression (before transplantation) and subsequently, with high doses of immunosuppression (after transplantation), the donor-specific CTLpf calculated by the CTLp-RR slightly decreased (Fig. 4: $P=0 \cdot 09)$. Tapering the dose of immunosuppression did not influence the CTLp-RR $(P=0 \cdot 33)$. The change in CTLp-RR was comparable between the patients converted to low dose AZA and those converted to low dose $\operatorname{MMF}(P=0 \cdot 19$; Table 1$)$.

\section{DISCUSSION}

After clinical transplantation, life-long immunosuppression is necessary. As minimizing immunosuppression is presumed to be beneficial, clinical trials were performed using conversion studies from CsA to AZA or MMF, avoiding or tapering one of the immunosuppressive drugs [6-10,12,13,30].

At present, it is not known whether T-cell reactivity will change after kidney transplantation and after subsequent routine tapering of immunosuppression. Therefore, we studied T-cell reactivity in patients who were converted from CsA to AZA or MMF, followed by successful AZA and MMF dose reduction. We measured T-cell reactivity before transplantation (no immunosuppression), during high dose immunosuppression (1 year after transplantation and treatment with CsA) and during low dose immunosuppression (2 years after transplantation: tapered AZA or MMF treatment). We showed that during high dose immunosuppression, donor-specific MLC-RR, HTLp-RR and CTLp-RR decreased, and TET-reactivity remained unchanged, compared 


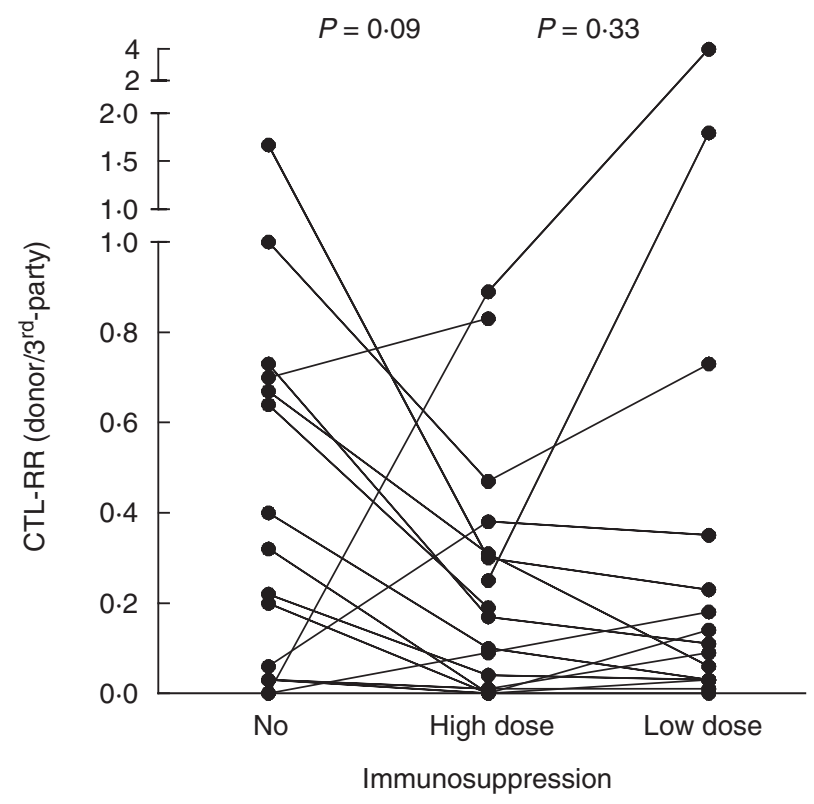

Fig. 4. Relative response (RR) in CTLp of 20 kidney transplant patients measured before transplantation (no immunosuppression), during treatment with high dose immunosuppression (1 year after transplantation: CsA treatment (trough level: $\pm 150 \mathrm{ng} / \mathrm{ml}$ ) and Pred $(10 \mathrm{mg} /$ day)), and during treatment with low dose immunosuppression (2 years after transplantation: $1 \mathrm{mg} / \mathrm{kg} /$ day AZA or $1 \mathrm{~g} /$ day MMF and Pred (10 mg/day)). No cells were available from two patients before transplantation and from two patients during treatment with low dose immunosuppression. The CTLpf assay of three patients were not reliable.

with the responses before transplantation (no immunosuppression). After successfully tapering the dose of immunosuppression, donor-specific MLC-RR, HTLp-RR and CTLp-RR remained unchanged, while TET reactivity increased significantly. Thus, in stable renal transplant recipients, donor-specific hyporeactivity is maintained, even after tapering immunosuppression. However, in some patients, the responses did not fit with the overall trends. We re-analysed the patients with MLC-RR, HTLp-RR or CTLp$\mathrm{RR}$ higher than 1 (i.e. donor response is higher than third-party response) during low dose immunosuppression until April 2001. We observed that the transplant of the one patient with high $(>1)$ MLC-RR failed by chronic rejection. The three patients with high HTLp-RR had no problems with graft function. The creatinine levels of the two patients with high CTLp-RR slowly increased and in their transplants, are signs of chronic rejection. We suggest that patients with low donor-specific T-cell reactivity may be candidates for further reduction of their immunosuppression.

Our MLC results confirm earlier studies comparing pre- and post-transplant MLC responses, in which $25-66 \%$ of renal transplant recipients had developed donor-specific hyporeactivity 1 year after transplantation [19,31-34]. Our data on donor-specific hyporeactive CTLp confirm earlier results obtained in patients with well-functioning kidney or heart allografts [16,35]. Additionally, Zanker et al. [24] described 19 kidney transplant recipients of whom only a few developed reduced T-cell reactivity; three patients developed reduced HTLpf, one patient reduced CTLpf, and two patients reduced HTLpf and CTLpf. De Haan et al. $[23,36]$ found a decrease in donor-specific CTLp 1-2 years after liver and lung transplantation compared with before transplantation, but this decrease did not correlate with decreased HTLp.

In line with our data on tapering immunosuppression, DeBruyne et al. [22] and Beik et al. [20] found a decrease of HTLpf relative to pre-transplant values. After successful withdrawal of steroids, the HTLpf remained low in three out three heart transplant patients [22] and seven out of nine renal transplant patients [20]. However, Creemers et al. [25] and Mazariegos et al. [26] demonstrated that the MLC-reactivity increased after discontinuation of CsA and after stopping immunosuppression, respectively. The first study [25] did not consider rejection episodes after discontinuation of CsA, and even suggested that the increased MLC response could be explained by the increased incidence of rejection following cessation of CsA; furthermore, they did not select patients who were successfully discontinued from CsA. The latter study [26] was performed in only two livingrelated renal transplant recipients.

Patients on chronic renal replacement therapy suffer from general immunosuppression, leading to a deficient response to T-cell dependent antigens, like hepatitis B, influenza and TET vaccination [37]. Consequently, the TET reactivity found during high dose immunosuppression is probably comparable with that before transplantation, as was shown in our patient group. In general, when patients are treated with low dose immunosuppression, the incidence of infection is lower than during treatment with high dose immunosuppression. This was also demonstrated by the increase of in vitro TET reactivity after tapering immunosuppression. In contrast to treatment with high dose immunosuppression, when patients will be exposed to the TET antigen in vivo during treatment, with low dose immunosuppression the immune system is capable of reacting. Another possible explanation for the high TET reactivity is the time after transplantation in combination with good graft function. We cannot exclude this explanation because in this study, we did not measure a control group of patients with stable graft function who remained on CsA therapy during the 2 years after transplantation.

In conclusion, donor-specific hyporeactivity can be found after transplantation and in stable renal transplant patients, even after tapering immunosuppression, although this latter is accompanied by an increased reactivity to non-HLA antigens such as TET. Consequently, tapering immunosuppression does not lead to an increase in donor-specific reactivity.

\section{ACKNOWLEDGEMENTS}

This study was supported by grant C95.1472 from the Dutch Kidney Foundation.

\section{REFERENCES}

1 Starzl TE, Klintmalm GBG, Weil R et al. Cyclosporin A and steroid therapy in sixty-six cadaver kidney recipients. Surg Gynecol Obstet 1981; 153:486-94.

2 Canadian Multicentre Transplant Study Group. A randomized clinical trial of cyclosporine in cadaveric renal transplantation. N Engl J Med 1983; 309:809-15.

3 European Multicentre Trial Group. Cyclosporin in cadaveric renal transplantation: one-year follow-up of a multicentre trial. Lancet 1983; 2:986-9.

4 Hamilton DV, Carmichael DJ, Evans DB, Calne RY. Hypertension in renal transplant recipients on cyclosporin $\mathrm{A}$ and corticosteroids and azathioprine. Transplant Proc 1982; 14:597-600. 
5 Kahan BD. Cyclosporine nephrotoxicity: pathogenesis, prophylaxis, therapy, and prognosis. Am J Kidney Dis 1986; 8:323-31.

6 Versluis DJ, Wenting GJ, Derkx FHM, Schalekamp MAHD, Jeekel J, Weimar W. Who should be converted from cyclosporine to conventional immunosuppression in kidney transplantation, and why. Transplantation 1987; 44:387-9.

7 Hollander AAMJ, van Saase JLCM, Kootte AMM et al. Beneficial effects of conversion from cyclosporin to azathioprine after kidney transplantation. Lancet 1995; 345:610-4.

8 Hall BM, Tiller DJ, Hardie I et al. Comparison of three immunosuppressive regimens in cadaver renal transplantation: long-term cyclosporine, short-term cyclosporine followed by azathioprine and prednisolone, and azathioprine and prednisolone without cyclosporine. N Engl J Med 1988; 318:1499-507.

9 MacPhee IA, Bradley JA, Briggs JD et al. Long-term outcome of a prospective randomized trial of conversion from cyclosporine to azathioprine treatment one year after renal transplantation. Transplantation 1998; 66:1186-92.

10 Smak Gregoor PJH, van Gelder T, van Besouw NM, van der Mast BJI, Jzermans JNM, Weimar W. Randomized study on the conversion of treatment with cyclosporine to azathioprine or mycophenolate mofetil followed by dose reduction. Transplantation 2000; 70:143-8.

11 Dantal J, Hourmant M, Cantarovich D et al. Effect of long-term immunosuppression in kidney-graft recipients on cancer incidence: randomised comparison of two cyclosporin regimens. Lancet 1998; 351:623-8.

12 Grinyo JM, Gil-Vernet S, Seron D et al. Steroid withdrawal in mycophenolate mofetil-treated renal allograft recipients. Transplantation 1997; 63:1688-90.

13 Kaplan B, Meier-Kriesche HU, Vaghela M, Friedman G, Mulgaonkar $\mathrm{S}$, Jacobs M. Withdrawal of mycophenolate mofetil in stable renal transplant recipients. Transplantation 2000; 69:1726-8.

14 Mazariegos GV, Reyes J, Marino IR et al. Weaning of immunosuppression in liver transplant recipients. Transplantation 1997; 63:243-9.

15 Devlin J, Doherty D, Thomson L et al. Defining the outcome of immunosuppression withdrawal after liver transplantation. Hepatology 1998; 27:926-33.

$16 \mathrm{Hu} \mathrm{H}$, Robertus $\mathrm{M}$, de Jonge $\mathrm{N}$ et al. Reduction of donor-specific cytotoxic $\mathrm{T}$ lymphocyte precursors in peripheral blood of allografted heart recipients. Transplantation 1994; 58:1263-8.

17 Goulmy E, Bittner K, Blokland E et al. Renal transplant patients with steroid withdrawal evaluated longitudinally for their donor-specific cytotoxic T cell reactivity. Transplantation 1991; 52:1083-5.

18 Burlingham WJ, Grailer AP, Fechner JH et al. Microchimerism linked to cytotoxic T lymphocyte functional unresponsiveness (clonal anergy) in a tolerant renal transplant recipient. Transplantation 1995; 59:1147-55.

19 Reinsmoen NL, Matas AJ. Evidence that improved late renal transplant outcome correlates with the development of in vitro donor antigen-specific hyporeactivity. Transplantation 1993; 55:1017-23.

20 Beik AI, Higgins RM, Lam FT, Morris AG. Steroid withdrawal and donor-specific hyporeactivity after cadaveric renal allotransplantation on maintenance triple therapy. Nephrol Dial Transplant 1997; 12:1949-55.

21 van der Mast BJ, van Besouw NM, Hepkema BG et al. Mutual tolerance after liver and not after heart transplantation? Evaluation of patient-anti-donor and donor-anti-patient responses by mixed lymphocyte culture. Transpl Immunol 1998; 6:33-8.

22 DeBruyne LA, Renlund DG, Bishop DK. Evidence that human cardiac allograft acceptance is associated with a decrease in donorreactive helper T lymphocytes. Transplantation 1995; 59:778-83.

23 de Haan A, van den Berg AP, Hepkema BG et al. Donor-specific hyporeactivity after liver transplantation: prominent decreases in donor-specific cytotoxic $\mathrm{T}$ lymphocyte precursor frequencies independent of changes in helper $\mathrm{T}$ lymphocyte precursor frequencies or suppressor cell activity. Transplantation 1998; 66:516-22.

24 Zanker B, Jooss-Rudiger J, Franz HE, Wagner H, Kabelitz D. Evidence that functional deletion of donor-reactive $\mathrm{T}$ lymphocytes in kidney allograft recipients can occur at the level of cytotoxic T cells, IL-2producing T cells, or both. A limiting dilution study. Transplantation 1993; 56:628-32.

25 Creemers P, Pascoe MD, Pontin AR, Kahn D. Rebound effect of the allogenic T-cell response to donor and third-party lymphocytes after cyclosporine withdrawal in renal transplant recipients. Transpl Immunol 1998; 6:261-4.

26 Mazariegos GV, Ramos H, Shapiro R, Zeevi A, Fung JJ, Starzl TE. Weaning of immunosuppression in long-term recipients of living related renal transplants: a preliminary study. Transplant Proc 1995; 27:207-9.

27 van Besouw NM, van der Mast BJ, de Kuiper P et al. Donor-specific Tcell reactivity identifies kidney transplant patients in whom immunosuppressive therapy can be safely reduced. Transplantation 2000; 70:136-43.

28 Deacock S, Schwarer A, Batchelor R, Goldman J, Lechler R. A rapid limiting dilution assay for measuring frequencies of alloreactive, interleukin-2-producing $\mathrm{T}$ cells in humans. J Immunol Methods 1992; 147:83-92.

29 Strijbosch LWG, Buurman WA, Does RJMM, Zinken PH, Groenewegen G. Limiting dilution assays. Experimental design and statistical analysis. J Immunol Methods 1987; 97:133-40.

30 Ratcliffe PJ, Dudley CR, Higgins RM, Firth JD, Smith B, Morris PJ. Randomised controlled trial of steroid withdrawal in renal transplant recipients receiving triple immunosuppression. Lancet 1996; 348:643-8

31 Creemers P, Du Toit E, Cassidy MJ, Kahn D. Sequential mixed lymphocyte culture after kidney transplantation: induction of tolerance or sensitization. Nephron 1997; 75:166-70.

32 Ghobrial II, Morris AG, Booth LJ. Clinical significance of in vitro donor-specific hyporesponsiveness in renal allograft recipients as demonstrated by the MLR. Transpl Int 1994; 7:420-7.

33 Wramner L, Mjornstedt L, Rydberg L, Olausson M. Cell-mediated immune responses in renal transplant recipients treated with cyclosporin and prednisolone with or without azathioprine. Scand J Immunol 1993; 37:656-60.

34 Kahn D, du Toit E, Jacobson JE, Creemers P. Induction of donorspecific tolerance or sensitization as measured by sequential MLC reactivity up to 24 months after renal transplantation. Transpl Int 1994; 7:S287-S289.

35 Herzog WR, Zanker B, Irschick E et al. Selective reduction of donorspecific cytotoxic $\mathrm{T}$ lymphocyte precursors in patients with a wellfunctioning kidney allograft. Transplantation 1987; 43:384-9.

36 de Haan A, van der Gun I, Hepkema BG et al. Decreased donorspecific cytotoxic $\mathrm{T}$ cell precursor frequencies one year after clinical lung transplantation do not reflect transplantation tolerance: a comparison of lung transplant recipients with or without bronchiolitis obliterans syndrome. Transplantation 2000; 69:1434-9.

37 Kimmel PL, Phillips TM, Simmens SJ et al. Immunologic function and survival in hemodialysis patients. Kidney Int 1998; 54:236-44. 